University of Nebraska - Lincoln

DigitalCommons@University of Nebraska - Lincoln

Faculty Publications, Department of Child, Youth, and Family Studies

$6-2020$

Participation in the CACFP Ensures Availability but not Intake of

Nutritious Foods at Lunch in Preschool Children in Child-Care

Centers

Saima Hasnin

Dipti Dev

Alison Tovar

Follow this and additional works at: https://digitalcommons.unl.edu/famconfacpub

Part of the Developmental Psychology Commons, Family, Life Course, and Society Commons, Other Psychology Commons, and the Other Sociology Commons

This Article is brought to you for free and open access by the Child, Youth, and Family Studies, Department of at DigitalCommons@University of Nebraska - Lincoln. It has been accepted for inclusion in Faculty Publications, Department of Child, Youth, and Family Studies by an authorized administrator of DigitalCommons@University of Nebraska - Lincoln. 


\title{
Participation in the CACFP Ensures Availability but not Intake of Nutritious Foods at Lunch in Preschool Children in Child-Care Centers
}

\author{
Saima Hasnin, ${ }^{1}$ Dipti A. Dev, ${ }^{1} \&$ Alison Tovar $^{2}$ \\ 1 Department of Child, Youth, and Family Science, \\ University of Nebraska-Lincoln, Lincoln, NE. \\ 2 Department of Nutrition and Food Sciences, \\ University of Rhode Island, Kingston, RI. \\ Corresponding author: Dipti A. Dev, PhD, Betti and Richard Robinson Associate Professor, \\ Department of Child, Youth, and Family Studies, University of Nebraska-Lincoln, \\ 255 Louise Pound Hall, Lincoln, NE 68588-0364. E-mail: ddev2@unl.edu
}

\begin{abstract}
Background - The US Department of Agriculture Child and Adult Care Food program (CACFP) recently (October 2017) updated requirements for meal reimbursement and best practice recommendations for serving nutritious meals and beverages, and minimum age-specific serving sizes for five food groups. It is not known whether CACFPfunded child-care centers are meeting the updated meal pattern requirements and best practice recommendations, and whether children are meeting nutrition recommendations based on the current 2015-2020 Dietary Guidelines for Americans (DGA). Objective This study assessed whether the recruited CACFP-funded child-care centers in this study were meeting the updated (2017) CACFP requirements regarding foods
\end{abstract}

Published in Journal of the Academy of Nutrition and Dietetics

doi: 10.1016/j.jand.2020.03.012

Copyright (C) 2020 by the Academy of Nutrition and Dietetics. Used by Permission. Submitted 17 April 2019; accepted 12 March 2020 
served for lunch and whether children attending these child-care centers were meeting ageand sex-specific DGA recommendations regarding foods consumed.

Design - This was a cross-sectional study using the Dietary Observation for Child Care method.

Participants and settings - Children aged 3 to 5 years (n 108) from 10 classrooms in three CACFP-funded child-care centers in Lincoln, NE, were recruited by convenience sampling during spring 2018 .

Measurable outcomes - Food served and consumed during observed lunches in comparison with updated CACFP requirements and DGA, respectively.

Statistical analysis - Adjusted mean amounts of foods served from each food group were compared with age specific minimum CACFP serving size requirements. Adjusted mean amounts of foods consumed from each food group were then compared with ageand sex-specific DGA recommendations.

Results - The recruited child-care centers were meeting the updated CACFP requirements regarding foods served but showed limited adherence to the best practice recommendations during the observed lunches. However, the overall mean intake for grains, fruits, and vegetables was significantly lower $(\mathrm{P}<0.01)$ than DGA recommendations. In addition, approximately $25 \%$ of the children did not consume any vegetables during their meal.

Conclusions - Although child-care centers were meeting the updated CACFP requirements by serving the recommended amounts of foods, children were not meeting DGA-recommended intakes. Future studies are needed to explore ways to improve adherence to best practice recommendations to improve children's consumption of healthy foods in child-care centers.

Keywords: Child-care centers CACFP, dietary intake nutrition, preschoolaged children food groups, dietary guidelines

\section{Research snapshot}

Research Questions: Are Child and Adult Care Food Program (CACFP)-funded child-care centers meeting CACFP requirements and best practice recommendations regarding foods served for preschool-aged children? Does preschool-aged children's dietary intake meet age-specific Dietary Guidelines for Americans (DGA) recommendations in CACFP-funded child-care centers? 
Key Findings: Child-care centers were meeting the updated CACFP meal pattern requirements but showed limited adherence to following CACFP best practice recommendations, such as-serving lean meats and family-style dining. In addition, children had limited intake of healthy foods based on DGA standards, specifically, mean consumption of fruits, vegetables, whole grains, protein, and dairy was significantly lower $(20 \%$ to $40 \%$; $<<0.001$ ) than DGA recommendations.

Early childhood is a critical period for developing dietary behaviors that track into adolescence and adulthood and is a strong predictor of long-term health status. ${ }^{1}$ Specifically, poor diet quality increases the risk of childhood obesity and associated chronic conditions such as diabetes and cardiovascular diseases. ${ }^{2}$ Unfortunately, the diet quality of preschool-aged ( 3 to 5 years) children in the United States, especially those from low-income families, ${ }^{3}$ fails to meet age-specific dietary recommendations. ${ }^{4}$ Specifically, preschool-aged children have a low intake of whole grains, legumes/beans, fruits and vegetables, and high consumption of refined grains and foods rich in sodium, sugar and empty calories. ${ }^{4}$ Therefore, better understanding of contributors to poor diet quality in this age group is important.

A large percentage (65\%) of preschool-aged children attend some form of nonparental care and of these, $81 \%$ attend center-based care. 5 Because it is recommended that children in full-time child-care centers consume about one-half to two-thirds of their daily calories in this setting, ${ }^{6-8}$ shaping this environment to ensure the availability of nutritious foods and beverages is critical. ${ }^{9,10}$ he food environment in this setting, the US Department of Agriculture Child and Adult Care Food Program (CACFP) recently (October 2017) updated meal pattern requirements and recommended best practices (Figure 1, available at www.jandonline.org ) to better align with the Dietary Guidelines for Americans 2015-2020 (DGA) ${ }^{11}$ and recommendations created by the National Academy of Medicine. ${ }^{12}$ CACFP is a federal food assistance program that offers financial reimbursement for meals, snacks, and beverages and professional development trainings to child-care settings caring for children from low-income families. ${ }^{12}$ CACFP provides nutritious meals and snacks to more than 4.2 million children daily, 


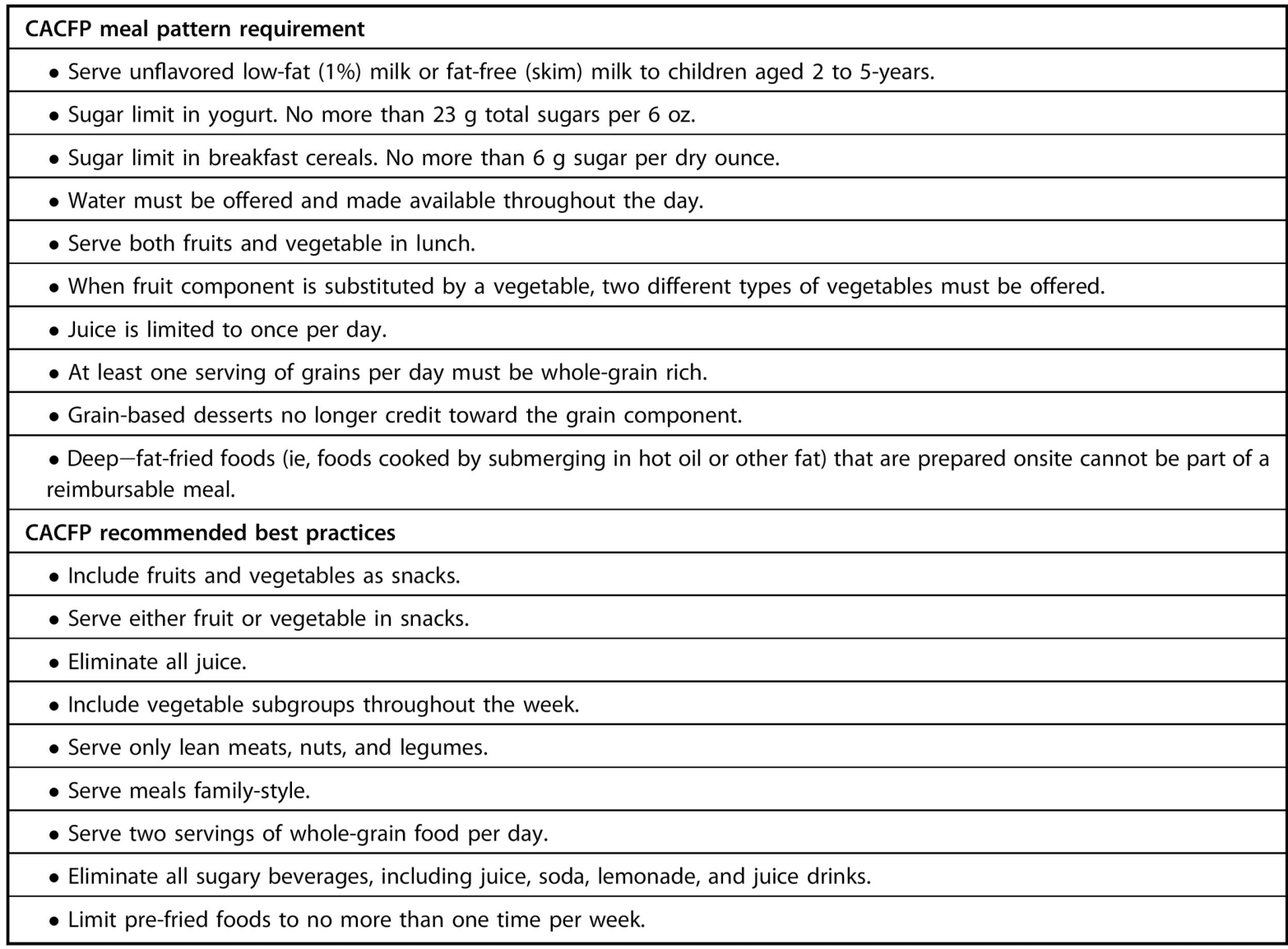

Figure 1. Updated Child and Adult Care Food Program (CACFP) Food and Nutrition Policy (October 2017) meal reimbursement requirements and recommended best practices

improving the overall nutrition environment of the child-care centers through updating and mandating policies regarding foods, beverages, and nutrition practices in child-care centers. ${ }^{12-14}$ The updated CACFP requirements for the participating child-care centers aims to ensure availability of both fruits and vegetables during lunches and dinner, less exposure to fruit juices and sugar restrictions in yogurt and breakfast cereals. ${ }^{12}$ The CACFP best practices are intended to be recommendations for the child-care providers, which include providing at least two servings of whole grains per day, not serving processed meats more than once per week, incorporating fruits or vegetables in snacks, eliminating all sugar-sweetened beverages and juices, serving family-style meals, and serving low-fat or natural cheeses. ${ }^{12}$ 
Studies conducted in child-care settings before the updated CACFP meal pattern requirements and best practice recommendations have shown that participation in CACFP was associated with serving nutritious meals and snacks to children. ${ }^{15,16}$ Although the quality of foods offered to children may be better in CACFP-funded child-care settings, ${ }^{15}$ other studies have found that despite having CACFP funding, best practice recommendations related to fruits, vegetables, processed meats, and low-fat cheeses and family-style meal service were not or were only partially being met by childcare centers. ${ }^{15,17,18}$ To the authors' knowledge, no studies have evaluated the adherence to the updated CACFP meal pattern requirements and best practice recommendations after their implementation. Given the high prevalence of CACFP-funded child-care programs in the United States, ${ }^{13}$ there is a need to assess whether child-care programs are meeting the new CACFP requirements and recommendations regarding foods served and whether children's dietary intake is consistent with DGA recommendations.

The first aim of this study is to assess whether CACFP-funded childcare centers are meeting the updated CACFP requirements, minimum portion sizes (for fruits, vegetable, grain, meat/meat alternates, and milk) and best practice recommendations for foods and beverages served to preschool-aged children at lunch. Given that CACFP policies are mandated to ensure only the minimum portion size requirements for the children and not the recommended daily intake, ${ }^{12}$ the second aim of this study is to compare preschool-aged children's dietary intake for the five food groups at lunch, which were targeted, updated CACFP requirements (fruits, vegetables, grain, meat/meat alternates, and milk), with age and sex-specific DGA recommendations. The current analysis was possible given that the data for this study were collected 6 months after the enactment of updated CACFP requirements. It was hypothesized that the foods being served to preschool-aged children ( 3 to 5 years) in child-care centers during lunch will be consistent with age-specific CACFP requirements for lunch. Given the prior literature showing that children in child-care settings are not meeting dietary recommendations, it was also hypothesized that the majority of the children will not be meeting age specific DGA recommendations at lunch. 


\section{Materials and methods}

\section{Participants and Settings}

The current study utilizes baseline data, collected during spring 2018, from the pilot evaluation of the Ecological Approach to Family Style Dining ${ }^{19}$ intervention pilot program. A convenience sample of three child-care centers was selected from the pool of recruited centers for the Ecological Approach to Family Style Dining intervention study to collect child level dietary data (n 10 classrooms, n 108 children, on average 36 children per child-care center). Inclusion criteria for the child-care centers included the following: the center needed to be CACFP-funded, serve preschool-aged children ( 3 to 5 years) full time, and provide lunches to the attending children. To recruit these centers, Nebraska Extension educators reached out to child-care center directors they had previously worked with and asked whether the program would be interested in participating in the study. Interested directors then helped recruit full-time child-care providers from their centers. Child-care providers who met the following inclusion criteria were recruited for the study: care for 3to 5-year old preschool children in the classroom and present with children during the lunch meal. No identifiable information was collected for the preschool children, so the parents were given an option to opt out of the study by signing and returning their forms within 2 weeks of distribution. Data were not collected from the children whose parents signed and returned the forms indicating they would like their child to opt out from the study.

After receiving the signed consent forms from the providers, the dietary intake observation was scheduled in consultation with the child-care directors at least 2 weeks after parents' consent forms were distributed. Children's lunch time dietary intake in the child-care centers was measured by the Dietary Observation for Child Care (DOCC) method. ${ }^{20}$ The directors were asked to provide demographic information (age, sex, and ethnicity and race) for the children in the participating classrooms. In addition, each provider completed a self-reported survey ${ }^{21}$ and one question in this survey inquired about the way meals and snacks are usually served to preschool-aged children in their classrooms with the following response options: meals and snacks are preportioned, provider portions out the servings to children, children serve some of the foods to themselves and other foods 
are preplated or portioned out by provider, and children always choose and serve most or all foods themselves. The data were de-identified after the data collection was completed and before the data analysis. The study was approved by the Institutional Review Board of University of Nebraska-Lincoln.

\section{Procedure for Dietary Intake Observation in ChildCare Center}

Before data collection, 12 observers received up to 12 hours of training to visually assess foods and beverages served and consumed (tablespoons or pieces for foods and ounces for beverage) in child-care centers, using the DOCC method. ${ }^{20}$ All trainees were students from University of Nebraska-Lincoln and were trained by a registered dietitian and experts on this protocol. ${ }^{22}$ For certification of the observers, an assessment of 20 foods and beverages was conducted before data collection in a lab setting. Interobserver reliability assessment and field certification were conducted by observing mealtimes in child-care centers as well. This training protocol and certification of the observers is based on previous studies that have utilized DOCC in child-care centers. ${ }^{22,23}$ One-sample $t$ tests were used to assess significant differences between the mean estimated portion by all 12 observers and the actual measured food portion by volume of the foods and beverage. Of the 20 items tested, five were assessed perfectly (all observers reported an identical amount as the actual portion) and 55\% of the items were measured accurately (observers reported the amount of the foods within 2 Tbsp error). ${ }^{20}$ However, all 12 observers reached at least $80 \%$ agreement with the actual measured portion for all food/ beverage items. Interobserver reliability on the assessment was determined by an interclass correlation with a two-way mixed model with absolute agreement and single measures. The reliability between observers across foods was high (interclass correlation $0.99 ; P<0.001$ ).

Before observing the children, data collectors explained to the providers that the purpose of the study was to only observe what children are eating for lunch and rather than assessing providers' practices. It was assumed that the observation days reflected usual serving and consumption at these centers. There were three to four tables in each of the 10 participating classrooms that were observed. The data collectors/observers to children ratio was 1:3 based on the DOCC protocol, ${ }^{20}$ and the number of data collectors present in each classroom varied 
Table 1. Demographic characteristics of observed children from 10 classrooms in three Child and Adult Care Food Program-funded Childcare Centers in Lincoln, NE (2018)

\begin{tabular}{|c|c|c|c|c|}
\hline Characteristic & $\begin{array}{l}\text { Overall } \\
(\mathrm{N}=108)\end{array}$ & $\begin{array}{l}\text { Center } 1 \\
(n=25)\end{array}$ & $\begin{array}{c}\text { Center } 2 \\
(n=32)\end{array}$ & $\begin{array}{c}\text { Center } 3 \\
(n=51)\end{array}$ \\
\hline & & $\mathrm{n}$ & & \\
\hline \multicolumn{5}{|l|}{ Sex } \\
\hline Male & $63(58.3)$ & $9(8.3)$ & $17(15 \cdot 7)$ & $37(34 \cdot 3)$ \\
\hline Female & $45(41.7)$ & $16(14.8)$ & $15(13.9)$ & $14(13)$ \\
\hline \multicolumn{5}{|l|}{ Age (y) } \\
\hline 3 & $49(45.4)$ & $12(11.1)$ & $14(13)$ & $23(21.3)$ \\
\hline 4 to 5 & $59(54.6)$ & $13(12)$ & $18(16.7)$ & $28(25.9)$ \\
\hline \multicolumn{5}{|l|}{ Race/ethnicitya } \\
\hline White & $93(86)$ & $21(22.6)$ & $27(29)$ & $45(48.4)$ \\
\hline Hispanic & $2(1.9)$ & $1(1)$ & $1(1)$ & o \\
\hline Black/African American & $2(1.9)$ & $\mathrm{o}$ & $2(1.9)$ & $\mathrm{O}$ \\
\hline Asian & $3(2.8)$ & $2(1.9)$ & $1(1.0)$ & $\mathrm{O}$ \\
\hline Mixed & $8(7.4)$ & $1(1)$ & $1(1)$ & $6(5 \cdot 7)$ \\
\hline
\end{tabular}

${ }^{a}$ Race/ethnicity of the children was reported by the director of the child-care center.

with the number of study children present at each day of the observation. On average, 15 children were observed per day at each center. In total, 14 lunches were observed from 10 classrooms in three childcare centers. Lunch observations were not scheduled during holidays or special occasions. Children in Center 1 and Center 2 were observed for five lunch time periods each. In Center 3 , the children were observed for four lunch periods. The observations occurred on nonconsecutive days. The numbers of children observed in each center are provided in Table 1. Each data collector selected three children sitting at the same table next to each other to observe and reported the amounts of foods being served and consumed by those children. ${ }^{20}$ Child's name and sex were noted for tracking purposes during the dietary intake observation. Foods served on the children's plates and beverages were measured and noted as foods served. Any spills and second servings were recorded immediately to calculate total amounts of foods served. After the mealtime, the remaining foods on their plates and beverages in cups were subtracted from the total foods served. Thus, the amount of foods consumed was calculated for each child immediately following the end of the meal. 


\section{Data Analysis}

Nutrient Assessment for the Served and Observed Foods in the ChildCare Centers. Two child-care centers prepared the foods onsite and one child-care center used catering services. The kitchen staff from both Center 2 and Center 3 were asked for detailed recipes. In addition, all nutrition information labels from food packages were noted. The recipes for the mixed dishes included individual amounts of each food group. Recipes for catered foods observed in Center 1 were estimated by a registered dietitian, using standardized recipes for school meals from the US Department of Agriculture website. ${ }^{24}$ The foods served to and consumed by each child were analyzed by Food Processor version 10.5.0.25 New recipes for mixed foods were created in the Food Processor program when an item was not found in the software database. For example, a sandwich recipe was prepared combining all the separate ingredients' information for cheese, ham slices, and bread slices. All servings were converted into ounce equivalents for protein from meat/meat alternates and grains and cups for milk, fruits, and vegetables. Cheese was considered as meat/meat alternates and included as an ingredient in the recipe for mixed dishes. Dairy included only the $1 \%$ low-fat milk.

To be able to compare whether the foods being served were meeting the updated CACFP requirements, food portions served were compared to the age-specific minimum serving sizes of the different food groups for lunch recommended by CACFP. ${ }^{12}$ Given that these recommendations only ensure minimum portion size requirements and not the recommended daily intake, ${ }^{12}$ to compare preschoolaged children's dietary intake for the five food groups, following previously published literature, the present study used one-third of the DGA as the standard to compare children's average intake for lunch. ${ }^{11,26}$ Because it is recommended for full-day child-care centers to provide children with $50 \%$ to $67 \%$ of their daily required intake through breakfast, lunch, and one snack. ${ }^{6,7}$ Based on previous literature and recommendations, breakfast is a smaller meal in child-care centers and when combined with a snack, it is considered one-third of the nutrient requirement needs. Thus, the remaining one-third of their daily requirement should be provided by lunch. ${ }^{27}$ The DGA age specific calorie standards were used, which is $1,200 \mathrm{kcal}$ for a 3-year old moderately active female child 
and 1,400 kcal for a 4to 5-year old moderately active male or female child. ${ }^{11,28}$ A moderately active child was chosen as the standard, given that previous studies have showed that more than 90\% CACFP-funded child-care centers engage children with outdoor active-playtime. ${ }^{28}$

Statistical Analysis. General linear modeling was performed in SAS, version $9.4 \mathrm{~m}^{29}$ to estimate mean differences between the amounts of served/consumed foods and the recommended amounts. The actual amounts for served and consumed foods were centered using the recommended values of each food group (Table 2) so that the outcome represented the deviation from the recommended value. Child age was dichotomized as 3 years versus 4 to 5 years and analyses were conducted separately by age group. This approach was used because recommendations for served and consumed foods are age-specific, so recommendations are different for 3-year old children vs 4 to 5-year old children. In addition, children were grouped into separate classrooms based on these age categories. Analyses were also conducted separately by food group because recommended values vary by food group. Although children were nested within childcare provider and child-care providers were nested within child-care centers, cluster sizes were not large enough to perform mixed modeling. Instead, child-care providers were treated as fixed effects and represented in the model by CT-1 dummy variables (with CT representing the number of childcare providers). Child-care providers were not included in the model because any information it would provide was redundant with the child-care provider effects. A test of whether the model intercept significantly differed from zero, holding constant the provider effects at the sample average, was used to determine whether the actual served/consumed values differed on average from the recommended values. Tests with a $\mathrm{P}$ value less than alpha 0.05 were considered statistically significant.

\section{Results}

A total of 108 children with a mean (standard deviation) age of 4 (0.57) years; range 3 to 5 years) from three CACFP funded child-care centers were observed for two lunches. Each of the classrooms had a minimum of six children and maximum of 14 children, with an average 


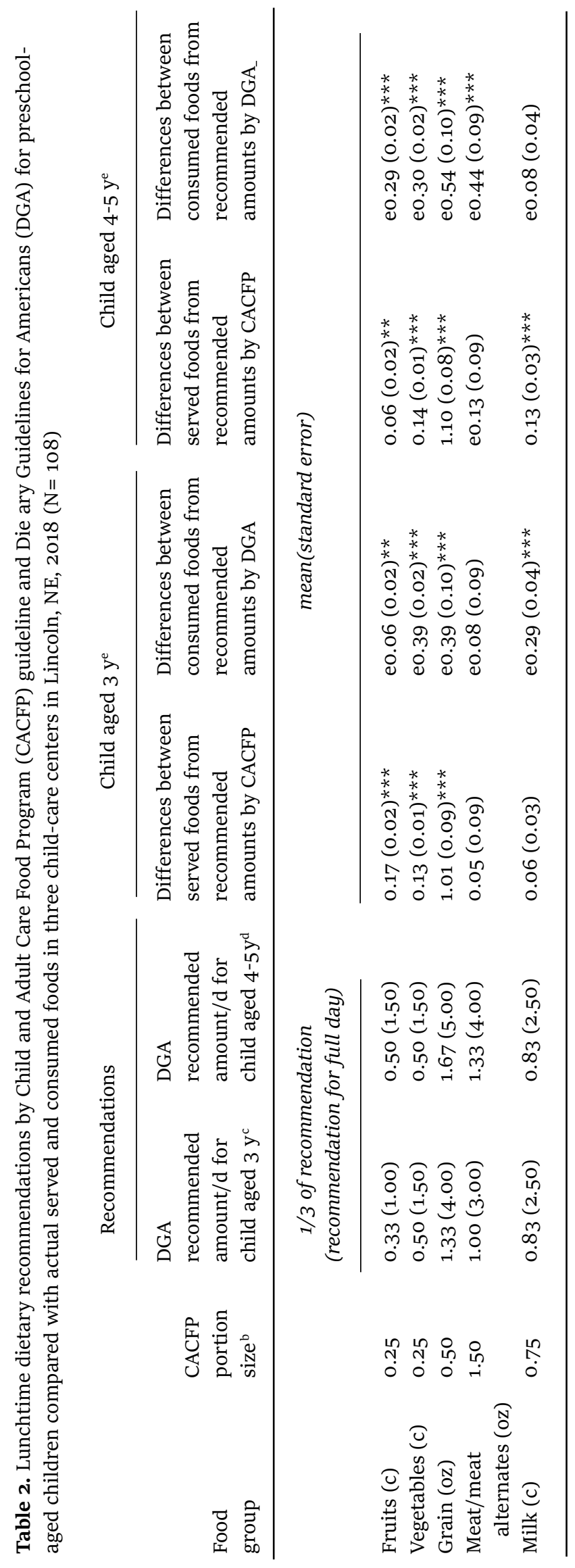


10.8 children per classroom. Approximately $86 \%$ of the total observed children were white and 14\% were Hispanic, African American, Asian, or mixed ethnic group (Table 1).

Food Served and Consumed in the Child-Care Classrooms. A total of 14 lunches were observed and at each of the lunches, grains, meat/meat alternates, vegetable, fruit and milk were served (Figure 2). The majority of the vegetables that processed onsite and served were either boiled, baked, or fresh vegetables and were prepared without frying and added salt. Mixed dishes (eg, pasta, spaghetti, rice, or chicken) were mostly oven baked or reheated in the microwave and included added condiments, sauces, and salt. Condiments offered to children with their meals included ranch dressing for fresh and baked vegetables, mayonnaise, and ketchup. However, no grain-based desserts, sugar sweetened beverages, juices, and yogurts were served at any of the lunches.

\section{Are Foods Served in Child-Care Meeting Updated CACFP Requirements and Best Practice Recommendations?}

The updated required age-specific minimum serving sizes offered to children from each food group are provided in Table $2 .{ }^{12}$ On average, all three child-care centers met required minimum amounts of servings for the fruits, vegetables, grains, and milk. The centers exceeded the minimum portion sizes for serving foods from these groups for both age groups $(\mathrm{P}<0.01)$. The mean amounts of meat/meat alternate served to the children aged 4 to 5 years and that for children aged 3 years were not statistically different from the CACFP required portion size (Table 2). For all lunches observed, 1\% low-fat milk and whole grains were served. In addition, all three centers had drinking water fountains, but water was not served during the lunches. No yogurt was served for any of the lunches observed. In addition, grain-based desserts, prefried or deep-fried foods were not served during the observed lunches.

Updated CACFP best practice recommendations were also being met in the classrooms: children were not served any juice and sugar sweetened beverages. However, one CACFP best practice recommendation that was not being met was the meat/meat alternate practice, whereby mostly deli meats and other processed meats were being 


\begin{tabular}{|c|c|}
\hline Food group ${ }^{a}$ & Foods served \\
\hline Grain & $\begin{array}{l}\text { Whole-wheat bread, whole-wheat bun, } \\
\text { whole-grain biscuits, whole-wheat } \\
\text { pasta, macaroni, whole-grain tortilla, } \\
\text { quinoa chips, dinner roll, rice }\end{array}$ \\
\hline $\begin{array}{l}\text { Meat/meat } \\
\text { alternates }\end{array}$ & $\begin{array}{l}\text { Scrambled egg, sausage gravy, ham } \\
\text { slices, turkey slices, burger, rotisserie } \\
\text { chicken, beef crumbles, regular cheese } \\
\text { slices, chicken patties, chicken } \\
\text { mandarin }\end{array}$ \\
\hline Milk & Low-fat (1\%) unflavored milk \\
\hline Fruit & $\begin{array}{l}\text { Canned oranges in light syrup, canned } \\
\text { mixed tropical fruits in light syrup, } \\
\text { fresh strawberries, fresh mixed fruit } \\
\text { salad, fresh pineapple, fresh } \\
\text { cantaloupe, canned peaches in light } \\
\text { syrup, fresh banana, fresh apple, } \\
\text { canned pears }\end{array}$ \\
\hline Vegetable & $\begin{array}{l}\text { Corn, hash brown, fresh bell pepper } \\
\text { strips, boiled green beans, broccoli } \\
\text { florets, mixed vegetables (peas, beans, } \\
\text { carrots), canned beans, celery sticks, } \\
\text { carrot sticks }\end{array}$ \\
\hline \multicolumn{2}{|c|}{$\begin{array}{l}{ }^{a} \text { The food groups are representing the groups used in the } \\
\text { Child and Adult Care Food Program guideline reports. }{ }^{11}\end{array}$} \\
\hline
\end{tabular}

Figure 2. Food groups of foods served for 14 observed lunches in three child-care centers in Lincoln, NE.

served. In addition, a significant proportion of providers (6o\%) were serving the children and deciding their portion sizes instead of following the CACFP best practice recommendations to serve lunches family style, where children serve themselves and select their own portions.

\section{Are Children in Child-Care Meeting DGA Requirements for Con- sumption of the CACFP Targeted Food Groups?}

Table 2 shows the mean differences of target food groups consumed from the DGA standards. For both 3-year old and 4to 5-year-old children, mean consumption of fruits and vegetables were significantly lower than the DGA recommendations. Fruit consumptions for 
children aged 3 years and 4 to 5 years were $0.06 \mathrm{c}$ and $0.29 \mathrm{c}$ less than the DGA recommendations, respectively. Approximately $25 \%$ of the children did not consume any vegetables and more than $75 \%$ of the children were not meeting the recommended intakes for vegetable (ie, $1 / 2$ c). On average, vegetable consumption for children aged 3 years and 4 to 5 years were $0.39 \mathrm{c}$ and $0.30 \mathrm{c}$ less than DGA recommendations, respectively. Consumption of whole grains were $0.39 \mathrm{c}$ and 0.54 c less than the DGA recommendation for children aged 3 years and 4 to 5 years, respectively (both $P$ values <0.001). The mean amounts of meat/meat alternate served to the 4to 5-year old children was about $0.44 \mathrm{c}$ less than the DGA recommendation and that for the 3-year old children were not statistically different from DGA recommendations. Unlike other food groups, children aged 4 to 5 years adequately met recommendation for milk consumption but 3-year old children on average consumed $0.29 \mathrm{c}$ less than the recommended amount of milk.

\section{Discussion}

The purpose of this study was to assess if CACFP-funded child-care centers are meeting the updated CACFP requirements, minimum portion size for each of the five food groups, and recommended best practice recommendations during lunchtime. Secondly, this study compared children's dietary intake for the five food groups, which were targeted with the updated CACFP meal pattern requirements, with age and sex-specific DGA standards. This study showed that child-care centers are meeting the updated CACFP minimum serving sizes, offering both fruits and vegetables during lunches, and are not serving grain-based desserts and prefried or fried foods, but the best practice recommendations are only partially being met. Although the children were not served sugar-sweetened beverages and juices, they were served mostly processed meats. Moreover, less than half of providers served family-style meal service, a CACFP best practice recommendation. Also, for the majority of children, recommended dietary intake for fruits, vegetables, and grains was not met. Similar to a previous study, ${ }^{17}$ the present study also suggests that revised CACFP meal pattern regulations have positively influenced the availability of foods from five food groups but not the implementation of best practice recommendations in CACFP-funded child-care centers. Despite the 
availability of these healthy foods, the majority of the children from both age groups did not consume the recommended amounts of fruits, vegetables, and grains based on DGA standards.

The CACFP-funded child-care centers in the current study served foods according to the updated CACFP requirements. Because CACFP requires the centers serve both fruits and vegetables to children during lunch, evidence suggests that CACFP-funded child-care centers tend to offer more vegetables and fruits to children than non-CACFPfunded centers. ${ }^{15}$ However, for most of the observed lunches in the present study, the CACFP best practice recommendation of serving lean meats was not met because processed meats were served more often than lean meats. Previous research findings are in congruence with this result, as Andreyeva and colleagues ${ }^{15}$ found that processed meats were served more frequently than lean meats even in CACFP-funded centers and the rate of serving lean meats vs processed meats during lunches has not been significantly different between the CACFP-funded and nonfunded centers. Thereby, to increase availability of lean meats, future CACFP revisions may consider mandating it as a requirement rather than a best practice recommendation. This is especially important because processed meats are categorized as "carcinogenic to humans" (group 1) by the World Health Organization ${ }^{30}$ and increases the risk of cardiovascular diseases in children by altering blood lipid profiles. ${ }^{31}$ Among other CACFP recommended best practices, the child-care providers were not implementing family-style dining. ${ }^{12}$ These findings are consistent with previous research reporting that CACFP funded child-care centers have a limited implementation of family-style dining. ${ }^{15,32}$ Although previous studies have found that there are barriers to serving meals family style in child-care settings, it is intended to help children with their self-regulation of food. Because children were being served healthy foods, yet not consuming them, it is possible that serving meals in this way could improve children's preference and consumption of available healthy foods and thus provide an avenue for meeting the DGA in CACFP funded programs. ${ }^{33,34}$

The average consumption of foods from all five food groups, particularly fruits and vegetables, were significantly lower than the DGA recommended amounts. Also, about $25 \%$ of the children did not consume any vegetables. Like other studies, children in this study consumed lower than recommended intakes for fruits and vegetables. ${ }^{4,7,27}$ 
Although it is encouraging to see that the updated CACFP policies are ensuring the availability for the minimum portion sizes of healthy foods, their recommended daily intakes for these foods are not being met. Ensuring that children meet these requirements is particularly important given that children are not meeting daily intake requirements for whole grains, fruits and vegetables away from the childcare center as well. ${ }^{35}$ Therefore, updating the policy and improving the availability of nutritious and healthy foods and beverages might not be enough to meet the age-specific daily recommended intake set by DGA. Despite the research showing that serving age-specific amounts for the entrée predicts higher consumption of fruits and vegetables, there is a need for strategies to increase consumption. ${ }^{36}$ Child-care providers may benefit from additional trainings on such strategies such as role modeling and encouragement. ${ }^{18,37}$ In addition, exploring alternate ways to prepare food so that children may be more likely to taste and consume these foods is warranted. Children's food preferences and dietary habits are influenced by many factors, including parents' food habits, preparation methods, socioeconomic status, and availability of healthy foods. ${ }^{36}$ Future research is needed to explore environmental and personal-level factors that influence children's dietary intake while they in the child-care center.

The study findings should be interpreted in light of the limitations. The data were collected from three CACFP-funded child-care centers in one city in Nebraska and may not be generalizable to other child-care settings or geographic locations. Because only lunches were observed in this study, the results do not represent overall intake of the children in child-care centers. Moreover, observing two lunches may not represent children's usual consumption throughout the whole week. Finally, child-care providers and children may behave differently because of the presence of the data collectors.

The strengths of this study include that a considerable number of children (n 108) were observed across different lunches. Actual recipes were collected from the child-care centers where available and actual amounts for both served and consumed foods were analyzed and compared with the standards. Moreover, exploring children's dietary intake pattern in Nebraska is important because of the high percentage of CACFP-funded child-care centers (78.5\%) $)^{38}$ and Nebraska ranks 13 th highest for early childhood obesity in the United States. ${ }^{39}$ 


\section{Conclusions}

This study found a disconnect between the availability and consumption of nutritious foods among children at child-care centers in Nebraska. These findings warrant future attention to help improve the CACFP meal pattern and incorporate additional strategies to improve consumption. Future research is needed to improve the implementation of CACFP recommended best practices such as family-style dining that can also offer an opportunity for improving children's consumption of the served foods based on CACFP requirements. Strengthening policies and providers' professional development training are needed to emphasize implementation of CACFP best practice recommendations along with the reimbursement requirements. Considering the varying policy-based contexts across child-care centers and different states, future studies can also explore comparing these findings to non-CACFP centers as well as other states.

\section{References}

1. Birch LL. Children's eating: The development of food-acceptance patterns. Young Child. 1995;50(2):71-78.

2. Xu S, Xue Y. Pediatric obesity: Causes, symptoms, prevention and treatment. Exp Ther Med. 2016;11(1):15-20.

3. Trevino RP, Vasquez L, Shaw-Ridley M, Mosley D, Jechow K, Pina C. Outcome of a food observational study among low-income preschool children participating in a family-style meal setting. Health Educ Behav. 2015;42(2):240-248.

4. Banfield EC, Liu Y, Davis JS, Chang S, Frazier-Wood AC. Poor adherence to US dietary guidelines for children and adolescents in the National Health and Nutrition Examination Survey population. J Acad Nutr Diet. 2016;116(1):21-27.

5. Kena G, Hussar W, McFarland J, et al. The condition of education 2016. https://nces.ed.gov/pubs2016/2016144.pdf. Accessed March 30, 2020.

6. Benjamin-Neelon SE. Position of the academy of nutrition and dietetics: Benchmarks for nutrition in childcare. J Acad Nutr Diet. 2018;118(7):1291-1300.

7. Erinosho TO, Hales DP, McWilliams CP, Emunah J, Ward DS. Nutrition policies at child-care centers and impact on role modeling of healthy eating behaviors of caregivers. J Acad Nutr Diet. 2012;112(1):119124.

8. American Academy of Pediatrics, American Public Health Association and National Resource Center for Health and Safety in Child Care and Early Education. Caring for Our Children: National Health and Safety Performance 
Standards: Guidelines for Early Care and Early Education Programs. Itasca, IL: American Academy of Pediatrics; 2002.

9. Story M, Kaphingst KM, French S. The role of child care settings in obesity prevention. Future Child. 2006;16:143-168.

10. Early Care and Education (ECE), Centers for Disease Control and Prevention. https://www.cdc.gov/obesity/strategies/childcareece. html. Updated 2020. Accessed March 30, 2020.

11. Dietary Guidelines for Americans 2015-2020. https://health.gov/ourwork/ food-nutrition/2015-2020-dietary-guidelines/guidelines/. Accessed March 30, 2020.

12. US Dept of Agriculture. Nutrition Standards for CACFP Meals and Snacks, https://www.fns.usda.gov/cacfp/meals-and-snacks. Accessed March 30, 2020.

13. Please revise this as: Food Research \& Action Center (FRAC). Child and Adult Care Food Program (CACFP), https://frac.org/programs/ child-adult-carefood-program. Accessed July 6, 2019.

14. Rida Z, Burger C, Dev D, Smith J, Hasnin S. Assessment of nutrition knowledge of childcare providers regarding the implementation of the 2017 CACFP meal pattern update. Am J Health Educ. 2018;49(6): 384-394.

15. Andreyeva T, Kenney EL, O'connell M, Sun X, Henderson KE. Predictors of nutrition quality in early child education settings in Connecticut. J Nutr Educ Behav. 2018;50(5):458-467.

16. Ritchie LD, Boyle M, Chandran K, et al. Participation in the child and adult care food program is associated with more nutritious foods and beverages in childcare. Child Obes. 2012;8(3):224-229.

17. Dave JM, Cullen KW. Foods served in child-care facilities participating in the child and adult care food program: Menu match and he new meal patterns and best practices. J Nutrc Behav. 2018;50(6):582-588.

18. Dev DA, McBride BA; STRONG Kids Research Team. Academy of Nutrition and Dietetics benchmarks for nutrition in childcare 2011: Are child-care providers across contexts meeting recommendations? J Acad Nutr Diet. 2013;113(10):1346-1353.

19. Dev D. Ecological approach to family style dining: A responsive feeding program for child care providers for improving children's dietary intake. $J$ Nutr Educ Behav. 2018;50(7).

20. Ball SC, Benjamin SE, Ward DS. Development and reliability of an observation method to assess food intake of young children in childcare. J Am Diet Assoc. 2007;107(4):656-661.

21. Hughes SO, Patrick H, Power TG, Fisher JO, Anderson CB, Nicklas TA. The impact of childcare providers' feeding on children's food consumption. J Dev Behav Pediatr. 2007;28(2):100.

22. Rasbold AH, Adamiec R, Anderson MP, et al. Macronutrient and micronutrient intakes of children in Oklahoma child-care centers, USA. Public Health Nutr. 2016;19(8):1498-1505. 
23. Sisson SB, Kiger AC, Anundson KC, et al. Differences in preschool-age children's dietary intake between meals consumed at childcare and at home. Prev Med Rep. 2017;6:33-37.

24. US Dept of Agriculture.Team Nutrition Recipes, https://www.fns.usda. gov/ tn/team-nutrition-recipes, Updated 22 May 2020. Accessed 25 May 2020.

25. The Food Processor, Nutrition Analysis and Fitness Software [computer program]. Version 10.50.o. Salem, OR: ESHA Research; 2016.

26. Frampton AM, Sisson SB, Horm D, Campbell JE, Lora K, Ladner JL. What's for lunch? an analysis of lunch menus in 83 urban and rural oklahoma childcare centers providing all-day care to preschool children. J Acad Nutr Diet. 2014;114(9):1367-1374.

27. Dixon LB, Breck A, Khan LK. Comparison of children's food and beverage intakes with national recommendations in new york city child-care centres. Public Health Nutr. 2016;19(13):2451-2457.

28. Sisson SB, Campbell JE, May KB, et al. Assessment of food, nutrition, and physical activity practices in oklahoma child-care centers. J Acad Nutr Diet. 2012;112(8):1230-1240.

29. SAS [computer program]. Version 9.4. Cary, NC: SAS Institute; 2017.

30. Bouvard V, Loomis D, Guyton KZ, et al. Carcinogenicity of consumption of red and processed meat. Lancet Oncol. 2015;16(16): 1599-16oo.

31. Rauber F, Campagnolo PDB, Hoffman DJ, Vitolo MR. Consumption of ultraprocessed food products and its effects on children's lipid profiles: A longitudinal study. Nutr Metab Cardiovasc Dis. 2015;25(1): 116-122.

32. Dev DA, McBride BA, Speirs KE, Donovan SM, Cho HK. Predictors of head start and child-care providers' healthful and controlling feeding practices with children aged 2 to 5 years. J Acad Nutr Diet. 2014;114(9):1396-1403.

33. Nicklas TA, Baranowski T, Baranowski JC, Cullen K, Rittenberry LT, Olvera N. Family and child-care provider influences on preschool children's fruit, juice, and vegetable consumption. Nutr Rev. 2001;59(7):224-235.

34. McBride BA, Dev DA. Preventing childhood obesity: Strategies to help preschoolers develop healthy eating habits. Young Child. 2014;69(5):36.

35. Robson SM, Khoury JC, Kalkwarf HJ, Copeland K. Dietary intake of children attending full-time childcare: What are they eating away from the child-care center? J Acad Nutr Diet. 2015;115(9):1472-1478.

36. Fisher JO, Dwyer JT. Next steps for science and policy on promoting vegetable consumption among US infants and young children. Adv Nutr. 2016;7(1):261S-271S.

37. Tovar A, Vaughn AE, Fallon M, et al. Providers' response to child eating behaviors: A direct observation study. Appetite. 2016;105:534-541.

38. Garcia AS, Dev DA, Stage VC. Predictors of parent engagement based on child care providers' perspectives. J Nutr Educ Behav. 2018;50(9): 905-912.

39. Obesity Rates Among WIC Participants Ages 2-4, The State https:// stateofchildhoodobesity.org/wic/. Updated November 2019. Accessed March 30, 2020. 


\section{Author information}

S. Hasnin is a doctoral degree student and D. A. Dev is a Betti and Richard Robinson Associate Professor, Department of Child, Youth, and Family Science, University of Nebraska-Lincoln, Lincoln, NE.

A. Tovar is an associate professor, Department of Nutrition and Food Sciences, University of Rhode Island, Kingston, RI.

Address correspondence to: Dipti A. Dev, PhD, Betti and Richard Robinson Associate Professor, Department of Child, Youth, and Family Studies, University of NebraskaLincoln, 255 Louise Pound Hall, Lincoln, NE 68588-0364. E-mail: ddev2@unl.edu

Statement of potential conflict of interest - No potential conflict of interest was reported by the authors.

Funding/support - This work was supported by the US Department of Agriculture National Institute of Food and Agriculture, Hatch Project No. 1011204, and the Nebraska Agricultural Experiment Station awarded to D. Dev.

Acknowledgements - The authors thank Dr. Susan B. Sisson for training on the Dietary Observation in Childcare Centers protocol and all the data collectors. The authors also thank Carly Hillburn and Jasmin A. Smith for their contribution in the data analysis process.

Author contributions - S. Hasnin and D. Dev collected the data. S. Hasnin wrote the first draft with contributions from D. Dev and A. Tovar. All authors reviewed and commented on subsequent drafts of the manuscript. 